\title{
PRODUKSI DAN APLIKASI ZAT WARNA ALAMI DARI KULIT KAYU MAHONI DAN KULIT KAYU TINGI UNTUK BATIK DI DESA KUWIRAN, KECAMATAN BANYUDONO, KABUPATEN BOYOLALI
}

\author{
Paryanto $^{1 *}$, Adrian Nur ${ }^{1}$ dan Desy Nurcahyanti ${ }^{2}$ \\ ${ }^{1}$ Program Studi Teknik Kimia, Fakultas Teknik, UNS \\ ${ }^{2}$ Program Studi Kriya Seni/Tekstil, FSRD, UNS \\ Jalan. Ir. Sutami Nomor : 36A Surakarta, 57126 \\ *Email : paryanto.uns@gmail.com
}

\begin{abstract}
Abstrak
Pengembangan penggunaan pewarna alami sebagai pewarna tekstil baru-baru ini meningkat. Ini karena pewarna alami ramah lingkungan dan mudah diperoleh. Ada sekitar 150 spesies tanaman yang secara intensif menghasilkan pewarna alami. Dari total spesies tanaman yang digunakan sebagai produsen pewarna alam termasuk kayu mahoni dan tingi. Pewarna alami kayu mahoni dan kayu tingi diaplikasikan pada kain 5 kali dan 10 kali pencelupan. Setelah itu penguncian warna pada kain dengan beberapa fixator. Fixator adalah tawas, ferro sulfat, dan kapur. Kemudian kain tetap diuji untuk tahan luntur warna mereka terhadap cucian, pewarnaan, gosok, uji penuaan warna kain, dan uji keringat asam. Hasil eksperimen dengan pencelupan 5 kali menghasilkan warna yang kurang tajam, sedangkan dalam mewarnai 10 kali menghasilkan warna yang lebih tajam dibandingkan untuk warna kain pada pencelupan 5 kali. Hasil analisis percobaan telah menunjukkan bahwa pewarna Mahoni dan Tingi diaplikasikan pada kain batik dan difiksasi menggunakan tawas fixator memiliki nilai evaluasi luntur warna yang optimal. Mengenali warna kain uji penuaan yang memiliki nilai R\% terkecil yaitu kain dicelup dengan pewarna mahoni pada pencelupan 10 kali dan difiksasi menggunakan fero sulfat dengan nilai $R$ 6,05. Sedangkan kain yang memiliki nilai $R \%$ tertinggi dari kain dicelup dengan pewarna mahoni pada pewarna ke-5 dan difiksasi menggunakan alum fiksator dengan nilai R\% sebesar 57,97. Analisis uji ketahanan warna terhadap keringat asam pada kain pewarna Tingi dengan pencelupan 5 kali, nilai perubahan warna kain memiliki skor Gray Scale (GS) 4-5 dengan evaluasi nilai BAIK. Nilai pewarnaan warna dari asetat, kapas, poliamida, poliester, akrilat, dan wol memiliki skor Gray Scale (GS) rata-rata 4 dengan evaluasi nilai BAIK.
\end{abstract}

Kata kunci: mahoni, ramah lingkungan, tingi

\section{PENDAHULUAN}

Pesatnya perkembangan industri batik tidak diiringi dengan kemajuan peralatan peralatan yang digunakan untuk proses produksi batik. Terlebih lagi di Usaha Kecil Menengah (UKM), peralatan yang digunakan masih tergolong kurang praktis dan efisien, sehingga berdampak terhadap kurang bagusnya warna dan sedikitnya produk yang dihasilkan. Lain lagi, apabila pabrik batik tersebut menggunakan zat warna alami sebagai pewarnanya, maka akan memerlukan waktu yang lebih lama, sehingga kecepatan produksinya terbatas. (Paryanto dkk., . 2015).

Studi kasus dilakukan di UKM yang terletak di Desa Kuwiran, Kecamatan Banyudono, Kabupaten Boyolali mengenai peralatan pencelupan dan fiksasi yang digunakan dalam proses produksi batik di UKM tersebut. Hasil studi lapangan didapatkan alat pencelup dan fiksasi di UKM , memiliki dimensi total $126 \mathrm{~cm} \times 79 \mathrm{~cm} \times 50 \mathrm{~cm}$, terdiri atas bak pencelup berbentuk trapesium, yang terbuat dari material seng ketebalan $0,3 \mathrm{~mm}$, bak pencelup diletakkan diatas bambu (bambu berfungsi sebagai penyangga bak). Volum bak adalah 50 liter. Untuk setiap kali pencelupan operator harus melakukan langkah diatas (roller) sebanyak $1-5$ kali. Biasanya operator melakukan pencelupan untuk selembar kain sebanyak 3-20 kali atau lebih tergantung selera warna yang diinginkan. Apabila dilakukan roller tiga kali untuk satu kali pencelupan, maka dibutuhkan waktu 19 menit. Sehingga alat hanya mampu digunakan untuk mencelup kain sebanyak 25 kali dalam sehari (delapan jam kerja/hari). Jika ukuran kain yang digunakan adalah 2 meter x 1,15 meter maka alat memiliki kapasitas pencelupan sebesar 57,5 $\mathrm{m}^{2}$ kain/hari.

Alat ini juga belum dilengkapi dengan media penirisan, sehingga apabila kain telah selesai dicelup didalam bak, kain langsung dijemur ditempat penjemuran tanpa ditiriskan 
terlebih dahulu, hal ini tentu menyebabkan hilang nya tetesan - tetesan zat warna atau fiksator, dan secara tidak langsung akan berdampak terhadap ongkos produksi. Rata rata zat warna yang dipakai untuk satu kali pencelupan adalah $340 \mathrm{ml}$ (3 kali roller) atau dengan kebutuhan spesifik pewarna 147,82 $\mathrm{ml} / \mathrm{m}^{2}$ kain.

Pada saat pencelupan di bak yang berisi zat warna alami atau fiksator, operator tidak dilengkapi dengan alat pelindung khusus, sehingga tangan mereka harus berinteraksi langsung dengan zat warna alami atau fiksator. Berdasarkan hasil wawancara dengan pihak UKM, operator mengeluhkan kulit tangan perih, gatal, dan bekas zat warna yang menempel pada tangan susah dihilangkan. Alat ini juga tidak dilengkapi dengan tongkat untuk penahan kain didalam bak, pada saat proses pencelupan maka kain akan mengembang didalam bak, sehingga menghasilkan pewarnaan yang kurang merata.

Selain alat yang kurang praktis dan efisien hal lain yang melatarbelakangi pembuatan alat pencelepuan dan fiksasi zat warna alami ini adalah peralatan yang ada sudah termakan usia (berkarat), karena terbuat dari bahan yang tidak tahan karat, telah digunakan semenjak tahun 2009 dan sudah selayaknya untuk diganti.

Pewarna alami dapat dihasilkan dari tumbuhan, seperti dari bagian batang, akar, daun, bunga, kulit batang, dan sebagainya. Terdapat sekitar 150 jenis tanaman yang intensif menghasilkan pewarna alami. Warna yang dihasilkan meliputi warna dasar (merah, biru, kuning) dan warna-warna kombinasi seperti coklat, jingga dan nila. Dari keseluruhan jenis tumbuhan yang digunakan sebagai penghasil zat warna alam diantaranya adalah kayu mahoni dan kayu tingi (Heyne,1987).

Penggunaan pewarna sintetis dapat menyebabkan pencemaran lingkungan dan merupakan bahan berbahaya, karena beberapa pewarna dapat terdegradasi menjadi senyawa yang bersifat karsinogenik dan beracun. Limbah industri tekstil penuh warna dan bahan kimia organik dari zat pewarna sintetis. Bercampurnya material koloid dengan limbah pewarna, dapat meningkatkan kekeruhan dan menjadikan air berpenampilan buruk, berbau, mencegah penetrasi sinar matahari. Dampak yang ditimbulkan adalah penipisan oksigen terlarut, kualitas perairan menurun dan kematian makhluk hidup yang tinggal di dalamnya karena kekurangan oksigen atau terkontaminasi senyawa beracun. Disamping itu ketika limbah dibiarkan mengalir akan menyumbat pori-pori tanah yang berakibat pada hilangnya produktivitas tanah, tekstur tanah mengeras dan mencegah penetrasi akar tumbuhan(Widjajanti dkk., 2011, Kant, 2012).

Penelitian ini menggunakan kulit kayu mahoni dan kulit kayu tingi. Pemilihan kulit kayu mahoni sebagai bahan pewarna batik didasarkan atas terdapatnya kandungan kimia pada kayu mahoni berupa flavoida yang merupakan pigmen penghasil warna coklat. Sedangkan pemilihan kulit kayu tingi sebagai bahan pewarna batik ini didasarkan atas terdapatnya kandungan tanin yang kerap digunakan sebagai bahan penyamak kulit dan bahan pewarna cat (Handayani dkk., 2013).

Kelemahan dari pewarna alami yaitu ketahanan lunturnya yang lebih rendah dari pewarna sintetis. Untuk memperoleh ketahanan luntur yang tinggi diperlukan proses fiksasi (pembangkitan warna) yang bertujuan untuk mempertajam warna dan supaya tidak mudah luntur.

Berdasarkan uraian tersebut, maka dilakukan penelitian berupa usaha pengikatan pewarna menggunakan bahan fiksasi berupa tawas, kapur, dan tunjung dengan konsentrasi dibawah $50 \mathrm{~g} / \mathrm{L}$. Pemilihan bahan fiksasi tersebut didasarkan pada sifat zat yang relatif tidak membahayakan lingkungan. Sebagai bahan pewarna alami digunakan kulit kayu mahoni dan kulit kayu tingi masing-masing dengan cara diekstraksi menggunakan alat ekstraktor-evaporator selama 2 jam dengan menggunakan pelarut air. Pada penelitian ini, pewarna alami yang dihasilkan diuji kualitas nilai ketahanan luntur warna terhadap gosokan kain basah dan kering, pencucian sabun dan penodaan, serta uji ketuaan warna.

Tujuan penelitian adalah mengetahui teknik pewarnaan zat warna alami pada kain batik, ketahanan luntur terhadap cucian, gosokan dan penodaan, serta mengetahui nilai ketuaan warna pada kain dengan menggunakan fiksator tawas, tunjung, dan kapur.

\section{METODE}

\section{Bahan}

Bahan yang digunakan antara lain zat warna kulit kayu mahoni, diperoleh dari Surakarta. Zat warna kulit kayu tingi diperoleh dari Kutawaru, Cilacap. Kain mori primisima 
diperoleh dari toko batik sekar arum, Laweyan, Surakarta. Kapur, tawas, dan tunjung, dan tunjung diperoleh dari toko Utama, Klewer, Surakarta.

Alat

Lounderometer, Crockmeter, Spektropotometer UV-PC.

\section{Prosedur Kerja}

Pada percobaan ini metode yang digunakan adalah pencelupan kain pada zat warna alami dengan menggunakan alat pencelup. Pada proses pencelupan, dilakukan variasi jumlah pencelupan yaitu 5 kali dan 10 kali pencelupan. Setelah dilakukan proses pencelupan, kain difiksasi menggunakan 3 jenis fiksator, yaitu kapur, tunjung, dan tawas. Kain kemudian diuji ketahanan luntur warnanya terhadap pencucian, gosokan, dan keringat asam serta diuji ketuaan warnanya.

\section{HASIL DAN PEMBAHASAN \\ Proses pewarnaan pada kain}

Proses pewarnaan pada kain batik menggunakan zat warna dari kulit kayu tingi dilakukan dengan perendaman selama 5 menit dengan variasi pencelupan 5 dan 10 kali. Hasil pencelupan sebagai berikut :

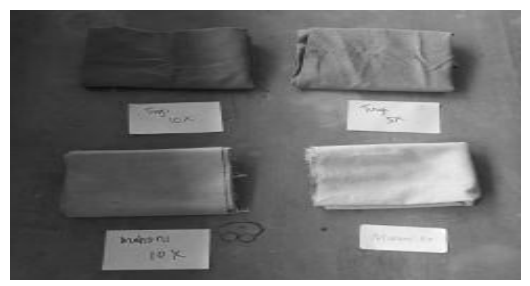

\section{Gambar.1 Hasil Proses Pencelupan 5 Kali dan 10 Kali}

\section{Proses Penguncian Zat Warna Alami pada Kain Batik}

Setelah dilakukan proses pencelupan dengan variasi pencelupan 5 dan 10 kali, kain dengan pencelupan 5 kali menghasilkan warna yang kurang tajam, sedangkan pada pencelupan 10 kali menghasilkan warna yang lebih tajam. Pada proses fiksasi yang dilakukan dengan menggunakan tiga fiksator yaitu tawas, tunjung, dan kapur pada masing-masing variasi pencelupan.

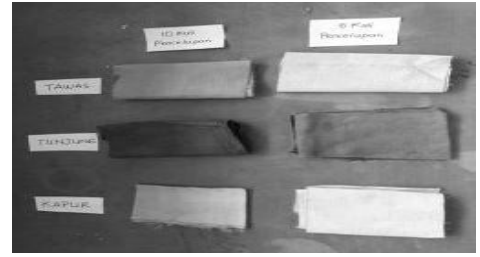

Gambar. 2 Hasil Proses Fiksasi Zat Warna Mahoni Menggunakan Tunjung, Tawas, dan Kapur

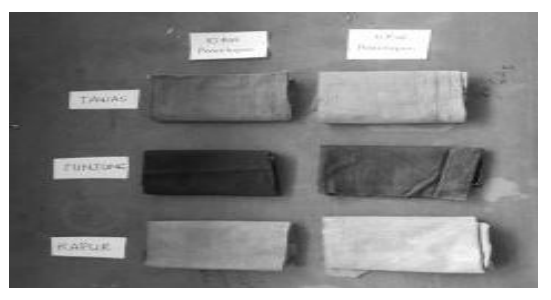

\section{Gambar.3 Hasil Proses Fiksasi Zat Warn Tingi Menggunakan Tunjung, Tawas, dan Kapur}

\section{Proses Pengujian Zat Warna pada Kain Batik}

Hasil pengujian zat warna dari kulit kayu mahoni dan kulit kayu tingi pada kain premis dilakukan dengan 6 cara yaitu pengujian kelunturan warna pada kain terhadap pencucian dengan Gray Scale (GS/CD), pengujian ketahanan luntur warna kain terhadap penodaan dengan Staining Scale (SS/CD), pengujian kain terhadap gosokan kering dengan Staining Scale (SS/CD), pengujian kain terhadap gosokan basah dengan Staining Scale (SS/CD), pengujian kain terhadap keringat asam, dan pegujian ketuaan warna kain. Proses pengujian terhadap pencucian menggunakan alat Lounderometer, proses pengujian terhadap gosokan menggunakan alat Crockmeter, sedangkan proses pengujian ketuaan warna menggunakan alat Spectophotometer UV-PC.

Hasil pengujian zat warna pada kain dapat terlihat pada Tabel.1 untuk hasil kelunturan warna terhadap pencucian dengan Gray Scale (GS/CD). Hasil pengujian kain terhadap penodaan dengan Staining Scale (SS/CD) dapat dilihat pada Tabel.2. Hasil pengujian kain terhadap gosokan basah dengan Staining Scale (SS/CD) dapat dilihat pada Tabel.3. Hasil pengujian kain terhadap gosokan kering dengan Staining Scale (SS/CD) dapat dilihat pada Tabel.4. Hasil uji ketuaan warna dapat dilihat pada Tabel.5. Hasil uji ketahanan 
luntur warna terhadap keringat asam dapat dilihat pada Tabel 6.

Tabel 1. Hasil Uji Ketahanan Luntur Warna Terhadap Pencucian dengan Gray Scale

\begin{tabular}{|c|c|c|c|c|c|c|c|}
\hline \multirow{4}{*}{$\begin{array}{c}\text { Jenis Zat } \\
\text { Warna }\end{array}$} & \multirow{4}{*}{$\begin{array}{l}\text { Jumlah } \\
\text { Pencelupan } \\
\text { (kali) }\end{array}$} & \multicolumn{6}{|c|}{ Fiksator } \\
\hline & & \multicolumn{2}{|c|}{ Tawas } & \multicolumn{2}{|c|}{ Tunjung } & \multicolumn{2}{|c|}{ Kapur } \\
\hline & & \multirow{2}{*}{\multicolumn{2}{|c|}{$\mathrm{CD}$}} & \multirow[t]{2}{*}{$\mathrm{SS}$} & \multirow[t]{2}{*}{$\mathrm{CD}$} & \multirow{2}{*}{\multicolumn{2}{|c|}{$\mathrm{CD}$}} \\
\hline & & & & & & & \\
\hline \multirow{4}{*}{ Tingi } & 5 & $4-5$ & 0,8 & $3-4$ & 2,1 & $3-4$ & 2,1 \\
\hline & Nilai & \multicolumn{2}{|c|}{ Baik } & \multicolumn{2}{|c|}{ Cukup baik } & \multicolumn{2}{|c|}{ Cukup baik } \\
\hline & 10 & $4-5$ & 0,8 & $3-4$ & 2,1 & 4 & 1,5 \\
\hline & Nilai & & & \multicolumn{2}{|c|}{ Cukup baik } & \multicolumn{2}{|c|}{ Baik } \\
\hline \multirow{4}{*}{ Mahoni } & 5 & 4 & 1,5 & $3-4$ & 2,1 & $3-4$ & 2,1 \\
\hline & Nilai & & aik & \multicolumn{2}{|c|}{ Cukup baik } & \multicolumn{2}{|c|}{ Cukup Baik } \\
\hline & 10 & 4 & 1,5 & $3-4$ & 2,1 & $3-4$ & 2,1 \\
\hline & Nilai & \multicolumn{2}{|c|}{ Baik } & \multicolumn{2}{|c|}{ Cukup baik } & \multicolumn{2}{|c|}{ Cukup baik } \\
\hline
\end{tabular}

Tabel 2. Hasil Uji Ketahanan Luntur Warna Terhadap Penodaan dengan Staining Scale

\begin{tabular}{|c|c|c|c|c|c|c|}
\hline \multirow{4}{*}{$\begin{array}{c}\text { Jenis } \\
\text { Zat } \\
\text { Warna }\end{array}$} & \multirow{4}{*}{$\begin{array}{l}\text { Jumlah } \\
\text { Pencelupan } \\
\quad \text { (kali) }\end{array}$} & \multicolumn{5}{|c|}{ Fiksator } \\
\hline & & \multicolumn{2}{|r|}{ Tawas } & Tunjung & \multicolumn{2}{|r|}{ Kapur } \\
\hline & & \multirow[b]{2}{*}{$S$} & \multirow{2}{*}{$\mathrm{CD}$} & \multirow{2}{*}{$\mathrm{CD}$} & \multicolumn{2}{|r|}{$\mathrm{CD}$} \\
\hline & & & & & $\mathrm{S}$ & \\
\hline \multirow{4}{*}{ Tingi } & 5 & 3 & 8 & 8 & $2-3$ & 11,3 \\
\hline & Nilai & \multicolumn{2}{|r|}{ Cukup } & Cukup & \multicolumn{2}{|c|}{ Kurang } \\
\hline & 10 & \multicolumn{2}{|r|}{8} & \multirow{2}{*}{8} & \multicolumn{2}{|c|}{8} \\
\hline & Nilai & \multicolumn{2}{|r|}{ Cukup } & & \multicolumn{2}{|c|}{ Cukup } \\
\hline \multirow{4}{*}{ Mahoni } & 5 & $3-4$ & 5,6 & 8 & $3-4$ & 5,6 \\
\hline & Nilai & \multicolumn{2}{|r|}{ Cukup baik } & Cukup & \multicolumn{2}{|c|}{ Cukup baik } \\
\hline & 10 & $3-4$ & 5,6 & 8 & 3 & 8 \\
\hline & Nilai & \multicolumn{2}{|c|}{ Cukup baik } & Cukup & \multicolumn{2}{|c|}{ Cukup } \\
\hline
\end{tabular}

Tabel 3. Hasil Uji Kelunturan Warna terhadap Gosokan Basah dengan Staining Scale

\begin{tabular}{|c|c|c|c|c|c|c|c|}
\hline \multirow{3}{*}{$\begin{array}{c}\text { Jenis } \\
\text { Zat } \\
\text { Warna }\end{array}$} & \multirow{3}{*}{$\begin{array}{l}\text { Jumlah } \\
\text { Pencelupan } \\
\quad \text { (kali) }\end{array}$} & & \multicolumn{5}{|c|}{ Fiksator } \\
\hline & & \multicolumn{2}{|r|}{ Tawas } & \multicolumn{2}{|c|}{ Tunjung } & \multicolumn{2}{|r|}{ Kapur } \\
\hline & & $\mathrm{S}$ & $\mathrm{CD}$ & SS & $\mathrm{CD}$ & SS & $\mathrm{CD}$ \\
\hline \multirow{4}{*}{ Tingi } & 5 & & 8 & 3 & 8 & 3 & 8 \\
\hline & Nilai & & Cukup & \multicolumn{2}{|c|}{ Cukup } & \multicolumn{2}{|r|}{ Cukup } \\
\hline & 10 & & 8 & 3 & 8 & 3 & 8 \\
\hline & Nilai & & Cukup & \multicolumn{2}{|c|}{ Cukup } & \multicolumn{2}{|r|}{ Cukup } \\
\hline \multirow{4}{*}{ Mahoni } & 5 & & 4 & 3 & 8 & 3 & 8 \\
\hline & Nilai & & Baik & & kup & \multicolumn{2}{|r|}{ Cukup } \\
\hline & 10 & \multirow{2}{*}{-4} & 5,6 & 3 & 8 & 3 & 8 \\
\hline & Nilai & & Cukup Baik & & kup & \multicolumn{2}{|r|}{ Cukup } \\
\hline
\end{tabular}


Tabel 4. Hasil Uji Kelunturan Warna terhadap Gosokan Kering dengan Staining Scale

\begin{tabular}{|c|c|c|c|c|c|c|c|}
\hline \multirow{3}{*}{$\begin{array}{c}\text { Jenis } \\
\text { Zat } \\
\text { Warna }\end{array}$} & \multirow{3}{*}{$\begin{array}{c}\text { Jumlah } \\
\text { Pencelupan } \\
\quad \text { (kali) }\end{array}$} & \multicolumn{6}{|c|}{ Fiksator } \\
\hline & & \multicolumn{2}{|r|}{ Tawas } & \multicolumn{2}{|c|}{ Tunjung } & \multicolumn{2}{|r|}{ Kapur } \\
\hline & & $\mathrm{S}$ & $\mathrm{CD}$ & $\mathrm{SS}$ & $\mathrm{CD}$ & SS & $\mathrm{CD}$ \\
\hline \multirow{4}{*}{ Tingi } & 5 & -4 & 5,6 & 3 & 8 & 3 & 8 \\
\hline & Nilai & & Cukup baik & & dkup & & Cukup \\
\hline & 10 & -4 & 5,6 & 3 & 8 & 3 & 8 \\
\hline & Nilai & & Cukup baik & & dkup & & Cukup \\
\hline \multirow{4}{*}{ Mahoni } & 5 & & 4 & $3-4$ & 5,6 & $3-4$ & 5,6 \\
\hline & Nilai & & Baik & & baik & & Cukup baik \\
\hline & 10 & & 4 & $3-4$ & 5,6 & $3-4$ & 5,6 \\
\hline & Nilai & & Baik & & baik & & Cukup baik \\
\hline
\end{tabular}

Tabel 5. Hasil Uji Ketuaan Warna Kain (Reflektansi = R\%)

\begin{tabular}{lcccc}
\hline \multirow{2}{*}{$\begin{array}{c}\text { Jenis Zat } \\
\text { Warna }\end{array}$} & $\begin{array}{c}\text { Jumlah } \\
\text { Pencelupan } \\
\text { (kali) }\end{array}$ & \multicolumn{3}{c}{ Fiksator } \\
\cline { 3 - 5 } & 5 & Tawas & Tunjung & Kapur \\
\hline \multirow{2}{*}{ Tingi } & 10 & 47,75 & 6,16 & R\% \\
& 5 & 47,01 & 8,31 & 27,38 \\
\multirow{2}{*}{ Mahoni } & 10 & 57,97 & 11,69 & 32,10 \\
& & 57,76 & 6,05 & 43,01 \\
\hline
\end{tabular}

Tabel 6. Hasil Uji Ketahanan Luntur Warna Terhadap Keringat Asam

\begin{tabular}{|c|c|c|c|c|}
\hline \multirow{2}{*}{ Jenis Uji } & \multicolumn{3}{|c|}{ Hasil Uji } & \multirow[t]{2}{*}{ Keterangan } \\
\hline & TJ 5 & TW 5 & K 5 & \\
\hline $\begin{array}{l}\quad \text { Nilai } \\
\text { perubahan } \\
\text { warna }\end{array}$ & $4-5$ & $4-5$ & $4-5$ & Baik \\
\hline \multicolumn{5}{|c|}{ Nilai penodaan warna } \\
\hline - Asetat & $4-5$ & 4 & 3 & Baik \\
\hline - Kapas & $4-5$ & 4 & 3 & Baik \\
\hline - Poliamida & $4-5$ & 4 & 3 & Baik \\
\hline - Poliester & $4-5$ & 4 & 4 & Baik \\
\hline - Akrilat & $4-5$ & 4 & $3-4$ & Baik \\
\hline
\end{tabular}

Berdasarkan Tabel. 1 hasil analisa pengerjaan tahan uji warna terhadap pencucian, diperoleh hasil bahwa pada pengujian kain menggunakan skala abu-abu, kain yang mempunyai ketahanan luntur yang optimal terhadap pencucian dengan Gray Scale adalah kain yang di fiksasi menggunakan fiksator tawas dalam zat warna mahoni maupun tingi karena mempunyai nilai ketahanan luntur yang $B A I K$ dalam variasi jumlah pencelupan yang dilakukan yaitu 5 kali dan 10 kali. Fiksator tunjung memiliki ketahanan luntur yang rendah dan mengalami perubahan warna pada saat pengujian, sehingga menyebabkan perbedaan warna yang signifikan dari warna aslinya.

Berdasarkan analisa tersebut dapat disimpulkan bahwa ketahanan luntur warna terhadap pencucian dengan Gray Scale adalah kain yang difiksasi menggunakan fiksator tawas dalam zat warna tingi maupun mahoni dengan pencelupan 5 kali maupun 10 kali.

Berdasarkan Tabel.2 hasil analisa percobaan ketahanan luntur warna terhadap penodaan dengan Staining Scale, kain yang memiliki tahan luntur warna yang optimal pada zat warna tingi adalah kain yang difiksasi 
menggunakan fiksator tawas dan tunjung dengan nilai 3 (CUKUP). Sedangkan kain yang memiliki tahan luntur warna yang optimal pada zat warna mahoni adalah kain yang difiksasi menggunakan fiksator tawas dengan nilai 3-4 (cukup baik). Kain dengan zat warna tingi yang difiksasi dengan fiksator kapur memiliki perubahan warna pada saat pengujian, sehingga

menyebabkan perbedaan warna yang signifikan dari warna aslinya.

Berdasarkan analisa tersebut dapat disimpulkan bahwa kain yang memiliki ketahanan luntur warna terhadap penodaan dengan staining scale yang optimal pada zat warna tingi adalah kain yang difiksasi menggunakan fiksator tawas dan tunjung dengan nilai 3 (Cukup). Sedangkan kain yang memiliki tahan luntur warna yang optimal pada zat warna mahoni adalah kain yang difiksasi menggunakan fiksator tawas dengan nilai 3-4 (CUKUP BAIK).

Berdasarkan hasil analisa pegujian tahan luntur warna terhadap gosokan basah yang disajikan dalam Tabel. 4 pada zat warna tingi kain yang mendapatkan hasil yang CUKUP adalah kain yang difiksasi menggunakan semua jenis fiksator pada pencelupan ke-5 maupun ke-10 dengan nilai 3 (CUKUP).

Berdasarkan analisa tersebut dapat disimpulkan bahwa pada zat warna tingi kain yang mendapatkan hasil yang CUKUP adalah kain yang difiksasi menggunakan semua jenis fiksator pada pencelupan ke-5 maupun ke-10 dengan nilai 3 (CUKUP). Sedangkan pada zat warna mahoni kain yang mendapat hasil yang $B A I K$ adalah kain dengan pencelupan 5 kali yang difiksasi dengan fiksasi tawas dengan nilai 4 (BAIK).

Berdasarkan hasil analisa pengujian tahan luntur warna terhadap gosokan kering yang disajikan dalam Tabel.4, kain yang dicelup zat warna tingi paling optimal adalah kain yang difiksasi menggunakan tawas pada jumlah pencelupan 5 kali dan 10 kali dengan nilai 3-4 (CUKUP BAIK). Sedangkan kain yang dicelup zat warna mahoni yang paling optimal adalah kain yang difiksasi menggunakan tawas pada jumlah pencelupan 5 kali dan 10 kali dengan nilai 4 (BAIK).

Berdasarkan analisa tersebut dapat disimpulkan bahwa pada zat warna tingi kain yang mendapatkan hasil yang CUKUP BAIK adalah kain yang difiksasi menggunakan fiksator tawas pada pencelupan ke-5 maupun ke-10 dengan nilai 3-4 (CUKUP BAIK). Sedangkan kain yang dicelup zat warna mahoni yang paling optimal adalah kain yang difiksasi menggunakan tawas pada jumlah pencelupan 5 kali dan 10 kali dengan nilai 4 (BAIK).

Berdasarkan data hasil uji ketuaan warna yang terdapat pada Tabel.5, kain yang memiliki nilai R\% paling kecil yaitu kain yang dicelup dengan zat warna mahoni pada pencelupan ke10 dan difiksasi menggunakan fiksator tunjung dengan nilai R\% sebesar 6,05. Sedangkan kain yang memiliki nilai $\mathrm{R} \%$ paling besar yaitu kain yang dicelup dengan zat warna mahoni pada pencelupan ke-5 dan difiksasi menggunakan fiksator tawas dengan nilai R\% sebesar 57,97.

Berdasarkan data diatas dapat disimpulkan bahwa kain yang memiliki nilai $\mathrm{R} \%$ paling kecil yaitu kain yang dicelup dengan zat warna mahoni pada pencelupan ke-10 dan difiksasi menggunakan fiksator tunjung dengan nilai $\mathrm{R} \%$ sebesar 6,05. Sedangkan kain yang memiliki nilai $\mathrm{R} \%$ paling besar yaitu kain yang dicelup dengan zat warna mahoni pada pencelupan ke-5 dan difiksasi menggunakan fiksator tawas dengan nilai R\% sebesar 57,97.

Berdasarkan hasil analisa pegujian tahan luntur warna terhadap keringat asam yang disajikan dalam Tabel.6 pada zat warna tingi kain dengan pencelupan 5 kali, nilai perubahan warna dari kain tersebut memiliki angka Grey Scale (GS) 4-5 dengan evaluasi nilai BAIK. Nilai penodaan warna terhadap asetat, kapas, poliamida, poliester, akrilat, dan wol memilik angka Grey Scale (GS) rata-rata 4 dengan evaluasi nilai $B A I K$.

\section{KESIMPULAN}

1. Pada Pencelupan 5 kali meghasilkan warna yang kurang tajam, sedangkan pada pencelupan 10 kali menghasilkan warna yang lebih tajam.

2. Bedasarkan pengujian ketuaan warna, kain yang memiliki nilai $\mathrm{R} \%$ paling kecil yaitu kain yang dicelup dengan zat warna mahoni pada pencelupan ke-10 dan difiksasi menggunakan tunjung dengan nilai $\mathrm{R} \%$ sebesar 6,05. Sedangkan kain yang memiliki nilai R\% paling besar yaitu kain yang dicelup dengan zat warna mahoni pada pencelupan ke-5 dan difiksasi menggunakan tawas dengan nilai $\mathrm{R} \%$ sebesar 57,97.

3. Berdasarkan pengujian ketahanan luntur warna terhadap keringat asam, pada zat warna tingi kain dengan pencelupan 5 kali, 
nilai perubahan warna dari kain tersebut memiliki angka Grey Scale (GS) yaitu 4-5 dengan evaluasi nilai BAIK. Nilai penodaan warna terhadap asetat, kapas, poliamida, poliester, akrilat, dan wol memilik angka Grey Scale (GS) rata-rata adalah 4 dengan evaluasi nilai BAIK.

\section{UCAPAN TERIMA KASIH}

Tim Pengabdian pada Masyarakat mengucapkan terima kasih kepada Ristek-Dikti atas pendanaannya dengan Kontrak No.020/SP2H/PPM/DRPM/2018, LPPM UNS, UKM Batik Soul Craf, UKM Batik Cantik sebagai tempat P2M, saudari Imas dan Fadillah yang telah membantu dalam melaksanakan program ini.

\section{DAFTAR PUSTAKA}

Handayani, P. A. Dan Maulan, I., (2013), Pewarna Alami Batik dari Kulit Soga Tingi (Ceriops Tagal) dengan Metode Ekstraksi, Journal Bahan Alam Terbarukan, 2(2) : 1-6.

Heyne, K., (1987), Tumbuhan Berguna Indoesia. Terjemahan Badan Libang Kehutanan, Jakarta Pusat : Koperasi Karyawan Departemen Kehutanan.

Kant, R., (2012), Textile Dyeing Industry an Environmental Hazard, Open Access Journal Natural Science, 4(1), Aticle ID 17027, 5 pages, DOI : 10.4236/ns.2012.41004.

Paryanto., dkk., (2015), Pengambilan Zat Warna Alami dari Buah Mangrove Spesies Rhizopora mucronata untuk Pewarnaan Batik Ramah Lingkungan, Jurnal Purifikasi.15(1): 34-40.

Widjajanti, E. Regina T.P., dan Utomo, M.P., (2011), Pola Adsorpsi Zeolit Terhadap Pewarna Azo Metil Merah dan Metil Jingga, Prosiding Seminar Nasional Penelitian, Pendidikan dan Penerapan MIPA. Fakultas MIPA, Universitas Negeri Yogyakarta. 